\title{
INSUFICIENCIAS DEL MODELO DEÍCTICO DE LOS NOMBRES PROPIOS
}

\author{
IGNACIO VICARIO \\ Departamento de Lingüística, Lenguas Modernas, \\ Lógica y Filosofía de la Ciencia \\ Universidad Autónoma de Madrid \\ ignacio.vicario@uam.es
}

RESUMEN: Discuto aquí un modelo del significado de los nombres propios desarrollado, principalmente, por Récanati y García-Carpintero. Según este modelo, los nombres propios son expresiones deícticas, que poseen una regla que atribuye al referente la propiedad de llamarse " $N$ ". La discusión se centra en la noción de significado lingüístico, la controversia deíxis/ambigüedad, el argumento de generalidad, el pretendido carácter no lingüístico de las estipulaciones nominales, y el papel de la propiedad metalingüística en la explicación de la competencia lingüística de los hablantes. Finalmente, critico la solución deíctica al problema de la comprensión y la transmisión de conocimiento.

PALABRAS CLAVE: significado lingüístico, deíxis, homonimia, estipulación nominal, comprensión

SUMMARY: I discuss here a model for the meaning of proper names developed, mainly, by Récanati and García-Carpintero. In this model, proper names are indexical terms, having a rule that describes the referent as being called "N". My discussion focuses on the notion of linguistic meaning, the controversy about indexicality/ambiguity, the generality argument, the claimed non-linguistic nature of naming conventions, and the role of the metalinguistic property in explaining the speakers' linguistic competence. Finally, I criticize the indexical solution to the problem of understanding and the transmission of knowledge.

KEY WORDS: linguistic meaning, indexicality, homonymy, naming convention, understanding

Aparentemente, los nombres propios son expresiones cuya única función semántica consiste en introducir en el discurso a su portador. Con ellos, más que con ninguna otra expresión, cobra sentido la vieja idea del lenguaje como un conjunto de etiquetas adheridas a las cosas.

Una posición semántica preeminente - conocida como Nueva teoría de la referencia - ha articulado teóricamente esta concepción ordinaria sobre los nombres propios, que llamaré teoría ingenua. Tres son las tesis que la caracterizan:

(T1) Los nombres propios son términos de referencia directa, en el sentido de que su valor semántico (su contribución a la condición de verdad en una oración simple) es tan sólo el objeto designado por el nombre. 
(T2) El referente del nombre es determinado por una práctica convencional que genera una cadena (causal) de comunicación, apoyada en una serie de actos de nominación.

(T3) Los nombres son términos millianos, en el sentido (no muy preciso) de que se limitan semánticamente a estar en lugar del objeto, sin describirlo o atribuirle propiedades que lo identifiquen.

Es conocida la amplia aceptación de que gozan las dos primeras tesis, y la controversia ocasionada por la tercera. A pesar de la verosimilitud que la concepción ordinaria le presta, con frecuencia se ha pensado que la tesis milliana no es capaz de ofrecer una explicación satisfactoria del hecho de que dos nombres correferentes puedan tener distinto valor cognoscitivo.

En este artículo me centraré en una de las teorías que recogen esa insatisfacción con (T3). Se trata del modelo deíctico de los nombres propios — representado principalmente por François Récanati y Manuel García-Carpintero- según el cual los nombres son expresiones sensibles al contexto, y deben tratarse (en buena medida) como expresiones deícticas. ${ }^{1}$ Así, cada nombre incorpora en su significado lingüístico un calificador descriptivo en forma de regla que permite la selección en el contexto de un referente para cada uso de la expresión. Este calificador atribuye al referente de un nombre, $N$, la propiedad metalingüística de ser llamado " $N$ ".

${ }^{1}$ Los análisis de Récanati (1993) y García-Carpintero (2000b, y —especialmente"The Mill-Frege Theory of Proper Names" (inédito) que amplía consideraciones apuntadas en 2000a) presentan notables semejanzas aparte de ser los más completamente articulados. Otros tipos de tratamientos deícticos relevantes son los de Burge (1973) y Pelczar y Rainsbury (1998).

Mi intención en este artículo es discutir un tipo de posición, no tanto debatir con propuestas específicas de un autor u otro. El trabajo publicado por Récanati responde plenamente a lo que (siguiéndolo a él) llamo "modelo deíctico". En cambio, los trabajos publicados por García-Carpintero sólo expresan muy someramente esa adecuación. Sólo en el manuscrito mencionado se aborda en profundidad y pormenorizadamente un análisis de los nombres propios en esa línea. La riqueza argumentativa y conceptual desplegada en ese texto me ha resultado extremadamente útil en cuestiones relevantes no elucidadas en detalle por Récanati, y justifican, creo, que lo haya utilizado para debatir la vía semántica abierta por el modelo deíctico. No obstante, debe tenerse presente en todo momento el carácter inédito de ese trabajo, todavía susceptible, por lo tanto, de revisión. En este sentido, García-Carpintero, en comunicación personal, me ha expresado que dicho manuscrito no recoge por completo sus opiniones actuales. Le agradezco que, a pesar de ello, me haya permitido su utilización. 
El modelo deíctico es una variante de la larga tradición de enfoques descriptivistas metalingüísticos por la que los nombres propios poseen una connotación metalingüística (enriquecida al ser usados con información contextual) que describe básicamente a su referente como portador del nombre en cuestión. ${ }^{2}$ Eso sí, se trata de una variante refinada a partir de las enseñanzas de la nueva teoría de la referencia, lo que le permite eludir las principales dificultades de la aproximación descriptivista. En particular, el modelo deíctico suscribe las tesis (T1) y (T2): acepta la primera, por cuanto el calificador descriptivo (o la connotación resultante en el uso del nombre) no es incorporado en el valor semántico; y la segunda, porque lo contextualmente seleccionado en un uso de un nombre es la práctica convencional que vincula el tipo de la expresión del nombre propio con un referente.

La credibilidad del modelo deíctico es manifiesta. Por un lado, no sólo es fiel a las más sólidas enseñanzas y argumentos surgidos de la nueva teoría de la referencia, sino que respeta, hasta cierto punto, la intuición ordinaria de que un nombre propio no describe sustantivamente a su referente. Por otro lado, gracias al papel otorgado al contexto, da pie a la aparición de diferencias cognitivas (entre nombres correferentes); además de darnos idea de cómo los hablantes logran manejarse con el hecho frecuente de que un mismo tipo de expresión de nombre propio pueda hallarse vinculado convencionalmente con un gran número de objetos.

A pesar de la proximidad del modelo deíctico con la teoría ingenua, las diferencias relativas a la estructura del significado lingüístico son notables. Mi propósito es mostrar que no está debidamente justificada la adopción de la propuesta deíctica. Para ello, empezaré por criticar algunos aspectos de esta propuesta (contrastándola con el modelo ingenuo); y abordaré la controversia entre deíxis o ambigüedad (argumentando en favor de lo segundo). A continuación examinaré las réplicas que se han aducido para neutralizar la principal objeción en contra de que el significado de los nombres incluya la propiedad metalingüística: el argumento de generalidad. Estas réplicas introducirán la cuestión del carácter y el funcionamiento de las prácticas que constituyen las convenciones o estipulaciones nominales, y su repercusión en la competencia lingüística de los hablantes. Al final, incluyo una breve discusión sobre un rompecabezas cognoscitivo que

${ }^{2}$ Destacados análisis descriptivistas metalingüísticos son los de Loar (1975), Bach (1987, 2002) y Katz (1994). 
sirve de apoyo a los partidarios del modelo deíctico: el problema de la comprensión y la transmisión de conocimiento.

\section{Significado lingüistico de los nombres propios}

De acuerdo con la concepción ingenua de los nombres propios, éstos tienen asociado de forma convencional un objeto: su referente. Ello produce un neto contraste con las expresiones deícticas, las cuales poseen una regla o calificador descriptivo que les procura en cada ocasión de uso un referente. ${ }^{3}$ La ausencia de un calificador descriptivo no debe hacer pensar que, en la teoría ingenua, los nombres no poseen significado lingüístico.

El significado lingüístico de una expresión está constituido por un conjunto algo heterogéneo de rasgos semánticos y sintácticos que de modo convencional están asociados a las expresiones y que, por lo tanto, son comunes a todo ejemplar de un determinado tipo lingüístico. Básicamente cabe distinguir entre dos tipos de elementos. Por un lado están los aspectos categoriales, aquellos que pertenecen a una expresión (tipo) por pertenecer a una determinada categoría gramatical. (Por ejemplo, si es un término singular o general; si es un pronombre o un adjetivo; el tipo de valor semántico que aporta a las condiciones de verdad, etc.). Por otro lado se encuentran los aspectos específicos, aquellos peculiares de la expresión (tipo) de que se trate. (A saber, si la expresión tiene asociado convencionalmente un objeto - o una extensión-, o por el contrario un calificador descriptivo que ayude a establecer un objeto para cada proferencia de la expresión; si incluye algún otro ingrediente, como por ejemplo un estereotipo u otro tipo de complejo atributivo — como en los términos de género natural-.)

Un nombre propio, en la teoría ingenua, posee ambos tipos de aspectos. Entre los categoriales contaría, por ejemplo, ser un término singular y ser referencial (en el sentido dado por (T1) sobre el tipo de contribución a la condición de verdad que realiza). Y entre los específicos incluiría únicamente el objeto (que designa) que está asociado a través de una convención o estipulación nominal a la expresión (tipo). Si un nombre es milliano en la teoría ingenua es (según la cla-

\footnotetext{
${ }^{3}$ El calificador descriptivo de, por ejemplo, el pronombre “yo" sería la regla:
}

(Y) Un ejemplar $e$ de "yo" designa a $x$ syss $x$ es el proferente de $e$. 
sificación propuesta) porque en los aspectos específicos no se incluye ninguna caracterización predicativa que trate de describir al objeto. ${ }^{4}$

El modelo deíctico configura el significado lingüístico de los nombres propios de un modo que remeda el de los deícticos. Los nombres propios no tienen asociado, como parte de los aspectos específicos de su significado lingüístico, un objeto, su referente, sino un calificador descriptivo. Lo que, en principio, trae consigo que los nombres propios, a pesar de ser expresiones directamente referenciales, no sean términos millianos, sino connotativos, como los deícticos. ${ }^{5}$ Aunque caben varias formas de detallarlo, dicho calificador fundamentalmente toma la forma de una regla de este tipo:

(M) Un ejemplar $e$ de un nombre propio de tipo " $N$ " designa a $x$ si, y sólo si, $x$ es el objeto seleccionado en la práctica (contextualmente destacada) de usar " $N$ " a la que $e$ pertenece. ${ }^{6}$

A semejanza de los deícticos, la designación de los nombres propios, de acuerdo con (M), se produce porque en el uso del nombre se destaca en el contexto una información que se precisa para establecer el referente de ese uso. (En este sentido, nombres propios y deícticos son expresiones reflexivas respecto del ejemplar.)

Sin embargo, (M) no hace que los nombres se comporten del todo como deícticos ordinarios. Mientras que en el caso de un deíctico el referente satisface una relación contextual con el ejemplar de la

${ }^{4}$ Puede argüirse la necesidad de que los nombres propios incluyan algún tipo de clasificador sobre el tipo de objeto que es el referente. Aunque no está claro que para todo nombre haya un término clasificador definido que deba ser conocido por los hablantes (especialmente cuando dejamos de lado los casos con objetos más reconocibles), la presencia o no de una cualidad semejante no es el eje sobre el que gira la cuestión de la connotatividad de los nombres propios, y puede ser aceptado por el milliano. Véanse Kripke 1980, pp. 115-116, n. 58, y Kripke 1979, p. 138, n. 9.

Por otro lado, en ocasiones, el hecho de que un determinado nombre haga referencia a cierto objeto se formula en forma de regla o propiedad. Así, por ejemplo, al nombre "Aristóteles" le correspondería la propiedad "referir-a-Aristóteles" ( $c f r$. Almog 1984). Esto no convierte el nombre en connotativo, pues con ello no se hace más que enunciar cuál es la función semántica del término, y no constituiría un auténtico elemento predicativo destinado a mediar en la obtención de la designación o a calificar al referente.

${ }^{5}$ Pero véase la nota 46.

${ }^{6}$ Esta formulación es una variación simplificada de la que ofrece GarcíaCarpintero (inédito). Récanati (1993): "Un ejemplar de NN refiere a la entidad que, en el contexto de proferencia, tiene la propiedad de portar el nombre tipo NN" (p. 141); y aclara que portar o ser llamado con cierto nombre (tipo) consiste en ser determinado en una práctica de uso del nombre (tipo) (cfr. p. 160). 
expresión proferido, relación que se circunscribe estrictamente a la proferencia de ese ejemplar, ${ }^{7}$ en el caso de los nombres propios la designación se basa en una previa relación convencional entre el tipo de expresión y el referente. Con ello, el modelo deíctico atiende a (T2), salvando así la diferencia semántica fundamental entre el mecanismo designativo de los nombres propios y el de las genuinas expresiones deícticas. Y es que los nombres, en expresión de Evans (1982, p. 373), no son términos "de una sola vez" [one-off]. La designación no se establece sobre la base de una aplicación aislada de la expresión; no depende de lo que hagan únicamente los hablantes que participan en el acto de habla, sino también de lo que anteriormente hicieron con el nombre (tipo) otros hablantes. Es necesario que la expresión utilizada sea un nombre del objeto, que exista una estipulación nominal, es decir, una práctica convencional de usar expresiones de ese tipo para nombrar a ese objeto. ${ }^{8}$ La práctica genera un entramado de dependencias entre los usos de unos hablantes y aquellos de los que los tomaron, dando lugar a una cadena (causal) de comunicación. Esta cadena (de acuerdo con (T2)) fija la referencia, el objeto asociado al nombre (tipo). El objeto fijado es aquel seleccionado (de un modo suficiente) en ciertos usos de la expresión (no necesariamente un único uso, un "bautismo", como en el esbozo kripkeano (1980, p. 91)): los actos de nominación, esto es, actos lingüísticos en los que junto a la proferencia del nombre ocurre una identificación del objeto realizada por otro medio que por la propia proferencia del nombre, ya sea por el uso de otra expresión (por ejemplo, "el hombre de la esquina es Juan") o por medio de una ostensión (por ejemplo, "ahí va Juan").

En definitiva, es característico de los nombres el sustentarse en estipulaciones nominales que vinculan al tipo de la expresión con un objeto. ${ }^{9}$ El modelo deíctico acomoda, pues, este hecho, por cuanto en el uso del nombre lo contextualmente seleccionado no es directamente el objeto, sino la práctica a la que el hablante se está adhiriendo.

${ }^{7}$ Véase la nota 3 .

${ }^{8}$ Salvo cuando se está introduciendo un nombre por vez primera, o cuando se realiza algún uso no literal, que explota algún mecanismo pragmático.

${ }^{9}$ Una de las principales dificultades del análisis de Burge (1973) es no respetar esta diferencia, no tener en cuenta (T2). Para éste, "Aristóteles casó con Pitíade" equivale a "Este Aristóteles casó con Pitíade"; y como con el uso del demostrativo, con el uso de "Aristóteles" el hablante llama la atención del oyente sobre un objeto de los que reciben el nombre "Aristóteles", a partir de alguna información contextual destacada, pero sin tener en consideración si ambos interlocutores se apoyan o no en una misma práctica lingüística. 
Por tanto, la designación del nombre se descompone en dos estadios lógicos: primero, el uso del nombre permite seleccionar en el contexto una estipulación nominal, y, segundo, esa estipulación determina un objeto. En el modelo ingenuo, el uso de un nombre designa, en un solo paso, un objeto por ser una expresión que pertenece a un determinado tipo lingüístico, vinculado (en una práctica convencional) con un objeto.

El contraste más llamativo que se establece respecto del modelo ingenuo es que el objeto designado por un nombre, al igual que ocurre con los deícticos, no es parte del significado lingüístico de éste. La exclusión del referente del significado lingüístico tiene repercusiones en cómo se individualizan los nombres propios con respecto a cómo procede la individualización en la teoría ingenua. En ésta, cada estipulación nominal contribuye a constituir el significado lingüístico de un nombre propio; con lo que, semánticamente, hay tantos nombres propios como estipulaciones nominales. ${ }^{10}$ Aristóteles, el filósofo de Estagira, y Aristóteles, el naviero millonario, tendrían en realidad nombres distintos, aunque homónimos. ${ }^{11} \mathrm{El}$ hecho de que una misma expresión, como ocurre con frecuencia, esté asociada con más de un portador se trata como un tipo de ambigüedad. ${ }^{12}$

En el modelo deíctico, por el contrario, los nombres no son ambiguos, por la misma razón que no lo son los deícticos; el hecho de que a más de un portador pueda aplicársele una misma expresión como nombre se explica como un tipo de deíxis, no de homonimia. En este modelo, el referente no es parte del significado lingüístico y hay tantos nombres propios como tipos de expresiones (a las que se aplica (M)). Ello quiere decir que todos los portadores del nombre "Aristóteles" tienen estrictamente el mismo nombre propio, con el mismo significado lingüístico.

${ }^{10}$ Las cadenas de comunicación generadas por la práctica convencional de uso del nombre es un factor clave en su individualización. Así, cabe distinguir nombres distintos que, no obstante, coinciden en la expresión y en el referente, algo que no podría hacerse si la individualización fuera meramente en virtud de sus propiedades ortográficas (y fonológicas) y del referente.

${ }^{11}$ En la teoría ingenua hay que distinguir entre lo que es en verdad un nombre propio, que tiene ya asignado un significado, de lo que no es más que la palabra que culturalmente - en una lengua o en varias - suele adoptarse para formar un nombre propio. Barajar expresiones de este último tipo es lo que suelen hacer los padres que están esperando un bebé; pero el nombre propio no queda constituido hasta que se conviene que una de esas expresiones sea el nombre del bebé.

${ }^{12}$ Cfr. Kripke 1980, p. 8; Kaplan 1989, p. 562; Evans 1982, p. 384; Perry 1997, p. 11. 


\section{Primeras dificultades para el modelo deíctico}

La incorporación de los nombres propios al modelo lingüístico que ofrecen las expresiones deícticas parece, en un primer momento, impropia, y suscita cierta extrañeza por distintos motivos.

(i) Ya la última afirmación de la sección anterior plantea dudas sobre la equiparación del significado lingüístico de nombres propios y deícticos. Observemos que en el modelo deíctico, en realidad, como la expresión (tipo) se halla cuantificada existencialmente en (M), a todo nombre propio le corresponde la misma regla, y, de esta manera, el mismo significado lingüístico. ${ }^{13}$ Pero esto no es igual en los genuinos deícticos, ya que a cada tipo de expresión le corresponde una regla o calificador descriptivo diferente. Así lo recoge Récanati: "Mientras que hay una única regla semántica para cada deíctico [...], hay una única regla semántica para todos los nombres propios [...]. Así parece que todos los nombres propios tienen el mismo significado" (1993, p. 142). ${ }^{14}$ La duda, o extrañeza, suscitada tiene que ver con el hecho de que si bien a la hora de individualizar los distintos tipos de deícticos son pertinentes sus respectivos significados lingüísticos (en particular, los calificadores descriptivos, que cambian de unos a otros), en el caso de los nombres propios el significado lingüístico (el calificador) no parece ser relevante en absoluto (pues es el mismo en todos), sino que para individualizar y distinguir un nombre propio de otro parece contar únicamente que la expresión (tipo) sea distinta.

(ii) Una dificultad relacionada, en parte, con la reflexión anterior es que (M) no parece que permita distinguir adecuadamente una palabra cualquiera de lo que es, diríamos (intuitivamente), un nombre propio. Obsérvese que un dato relevante de la categoría de los nombres propios es la permisión con la que cualquier palabra ("Pichurri", "C3PO") o conjunto de palabras (aunque tengan previamente otra función gramatical y semántica: "Bebé", "El hombre de las nieves", "Organización de Naciones Unidas") puede constituirse en nombre propio. Pero no parece que un nuevo nombre propio se constituya simplemente por la adopción de un nuevo tipo de expresión. Hace falta para quedar así constituido que se asiente, convencionalizándose, en una práctica de uso apropiada. ${ }^{15}$ Así, dada una expresión de nuevo

\footnotetext{
${ }^{13}$ Por ello, en realidad, en este modelo el calificador descriptivo podría verse como un elemento categorial, antes que específico, del significado lingüístico.

${ }^{14}$ Similar reconocimiento de esta diferencia se halla en García-Carpintero inédito.

${ }^{15}$ También en el caso de los nombres propios vacíos (como "Papá Noel" o "Pegaso"), en los que la práctica descansa sobre actos de nominación que no llegan a fijar un objeto (y acaban - en términos de Donnellan-en un bloque). En la
} 
cuño, como por ejemplo, "Biririrí", para la que no haya práctica alguna que constituya una estipulación nominal, no diríamos que es un nombre propio (no lo es efectivamente en el modelo ingenuo en el que la práctica convencional procura el establecimiento de un ingrediente del significado lingüístico de los nombres); pero no se ve claro por qué no habría de serlo respecto del modelo deíctico. El calificador descriptivo (M) (junto con los ingredientes categoriales que se precisen) no parece explicar adecuadamente el tránsito de una expresión cualquiera a un nombre propio. Pues, en principio, (M) parece asegurar un significado lingüístico para cualquier expresión (tipo) a la que se aplique la regla, con independencia de que haya alguna estipulación a fin de usar la expresión como nombre propio de algún pretendido objeto; ya que la práctica convencional que liga expresión y referente queda relegada a ser un mero elemento del contexto (incluso un elemento no lingüístico del contexto -véase más sobre esto en la sección 4.1-), un elemento cuya función no es procurar la constitución de ningún ingrediente del significado lingüístico del nombre.

\section{Estipulaciones nominales, homonimia y deíxis}

Con frecuencia, una misma expresión (tipo) de nombre propio se halla asociada por medio de varias estipulaciones convencionales con diversos objetos. Dependiendo del contexto, un uso de "Juan" puede hacer referencia a más de una persona. En el modelo deíctico, al proferirse un ejemplar del nombre se selecciona contextualmente una estipulación; y esta remisión al contexto es asimilada a la de un deíctico.

Un modo conocido de objetar esta asimilación es el siguiente (Kaplan 1989 y Perry 1997). Hay dos maneras en que puede ser precisa la intervención del contexto. La apelación que se produce cuando a una expresión (tipo) de nombre propio le corresponden varias estipulaciones convencionales (como la que se produce cuando una expresión adjetiva o de nombre común tiene más de una acepción) es una apelación presemántica; en la que se esclarece qué palabra (de qué lengua) y con qué significado se ha proferido. La situación de los deícticos dista de ser ésta. Su remisión al contexto es semántica; se produce una vez establecido el significado, y por exigencia de ese mismo significado. La objeción puede recapitularse con un célebre

introducción de un nombre propio (normalmente) la práctica se inicia con algún acto de nominación (extremo que no encontramos en "Biririrí", ejemplo que expongo a continuación). 
díctum: "un nombre no se emplea con el gesto demostrativo, sino que sólo se explica por medio de él" (Wittgenstein 1953, § 45).

Ciertamente, es una cuestión delicada - como reconoció Kaplan (1989, p. 562) - decidir si la apelación al contexto es presemántica o parte del significado lingüístico de una expresión. Merece la pena que nos detengamos en señalar algún pro, y en atajar un contra, relativos a la primera interpretación.

(i) A diferencia de lo que sucede con los auténticos deícticos, en los nombres no hallamos sistematicidad ninguna en cuanto al tipo de factor contextual que ha de indicar al oyente, en cada caso, qué objeto es el designado. Como dice Searle (1958, p. 252), "un nombre propio hace referencia sin presuponer ningún arreglo del escenario o ninguna condición contextual especial que rodee la proferencia de la expresión". Esto no es así con los deícticos, los cuales se valen, normalmente, de circunstancias creadas por la propia situación de habla, y que no permanecen de un contexto a otro. ${ }^{16}$

(ii) La información o el dato contextualmente destacado en el uso de la expresión desempeña un papel distinto en función de si la expresión es un nombre propio o un deíctico. Y es que mientras que corrientemente, en el uso de un deíctico, el dato destacado en el contexto de proferencia determina (semánticamente) la referencia, eso no es estrictamente así en el uso de un nombre. Veamos la diferencia. En una proferencia de "Ese individuo es un espía", la información perceptual contextualmente destacada es responsable de determinar el referente del demostrativo. ${ }^{17}$ Por otro lado, en el uso de un nombre se produce una connotación formada básicamente por la información meramente lingüística aportada por $(\mathrm{M})$ y, además, por algún dato normalmente de carácter predicativo (general), contextualmente saliente, encaminado a restringir una práctica de las asociadas con el tipo de expresión. Ahora bien, esa connotación predicativa resultante (que sirve a los hablantes para restringir la práctica) no es suficiente por sí misma para determinar (semánticamente) el referente de la expresión; ese papel les corresponde a los actos de nominación que

\footnotetext{
${ }^{16}$ Bach (2002, p. 91): "la relación nombre-portador no es sensible al contexto en absoluto: un nombre guarda esta relación hacia todos sus portadores, no simplemente hacia aquel al que el hablante trata de hacer referencia al usar [el nombre] en el contexto. Lo que es sensible al contexto es la relación hablante-referente, pero ésta no es la relación invocada en la regla de Récanati"; o (cabe añadir) en (M).

${ }^{17} \mathrm{Y}$ por ello alguien que oyera a sus espaldas la proferencia no sería capaz de dar con el referente ni, en consecuencia, con el estado de cosas aseverado. Cfr. Perry 1988, p. 237.
} 
se hayan producido en la cadena de comunicación en la que se apoya el uso del nombre (conforme a (T2)). ${ }^{18}$

Estos dos puntos, en mi opinión, favorecen la interpretación por la que el dato aportado por el contexto en el establecimiento de la estipulación de que se vale el hablante antes cumple la función de despejar una homonimia, que la de determinar o fijar la referencia. Al fin y al cabo, los nombres propios, al igual que, por ejemplo, los nombres comunes ("monitor", "caballo") o adjetivos ("rojo"), se constituyen sobre estipulaciones nominales que vinculan sus valores semánticos al tipo de la expresión. (Y para despejar la variedad de acepciones de "monitor" no se viene a adoptar un modelo deíctico análogo.) No ser ni unas ni otras expresiones de una sola vez supone un rasgo diferencial claro respecto de los deícticos.

No obstante (y aquí va el contra), los nombres propios presentan una singularidad que cabe ver como un inconveniente para la tesis de la ambigüedad. El número de estipulaciones nominales (y de portadores) asociado con una expresión (tipo) de nombre propio suele ser muy elevado (respecto del de estipulaciones de una expresión de nombre común). ${ }^{19}$ Este factor introduce una falla en la comparación establecida que alienta la equiparación de los nombres propios con los deícticos (donde a un número aún más copioso de objetos le cabe ser la referencia de otros tantos usos de un mismo tipo de expresión deíctica). ${ }^{20}$

A pesar de ello, creo más apropiado hablar de homonimia con relación a los nombres propios. La razón es simple: es accidental a los nombres propios que varios objetos sean llamados con la misma expresión (tipo). Desde un punto de vista lingüístico, no es intrínseco

${ }^{18}$ García-Carpintero (inédito) es especialmente explícito al respecto de la señalada insuficiencia identificadora del dato predicativo. En realidad, para el establecimiento de la estipulación relevante (y por lo tanto del referente), resulta clave el propio ejemplar proferido y su vinculación (causal) con una cadena de comunicación. Por eso, en mi opinión, la connotación predicativa resultante tras la proferencia aspira únicamente a resolver la cuestión epistemológica de saber cuál es la práctica convencional pertinente, pero no la semántica. Una muestra de ello es que no tiene importancia, a fin de restringir la práctica, que el dato predicativo contextual sea impreciso o incluso una falsedad habitualmente atribuida al referente; como, por ejemplo, "el inventor de la guillotina", respecto de Guillotin. Véase la sección 5 para más detalles sobre la connotación o modo de presentación contextualmente enriquecido.

${ }^{19}$ Véanse Burge 1973, Récanati 1993, Voltolini 1995, y Pelczar 2001.

${ }^{20} \mathrm{Al}$ intento de distanciar nombres propios y comunes se añaden dos razones más: no son, los primeros, parte de la lengua, y su desconocimiento no hace incompetente a un hablante. Véase la sección 4.1. 
al modo de significar de los nombres propios, como no lo es al de los comunes o adjetivos, que la misma expresión se aplique a más de una entidad; por todo lo que concierne a ese su modo de significar bien pudiera suceder de otra manera: bastaría adoptar una expresión nueva cada vez que se introduce una estipulación nominal. ${ }^{21}$

Nada parecido puede afirmarse de los deícticos. Justamente porque no tienen asignados sus referentes en virtud de estipulaciones nominales, en su caso no es accidental que puedan aplicarse a más de un referente, sino que esta posibilidad es el resultado de su particular modo de significar (de su tener que instituir un referente en cada uso).

Así, mientras, por un lado, aquello por lo que se semejan los nombres propios a los nombres comunes (o de otro modo, aquello por lo que nombres propios y deícticos se diferencian), esto es, la existencia de estipulaciones nominales, es intrínseco a su modo de significar; por el otro, el aspecto por el que se diferencian ambas categorías de expresiones (y, por ende, la fuente de semejanza entre nombres propios y deícticos), esto es, el elevado número de posibles referentes, es accidental. Y, por ello, la homonimia parece una opción más justificada para los nombres propios que la deíxis. ${ }^{22}$

\section{El argumento de generalidad y la competencia lingüística}

El obstáculo más fuerte para la aceptación del análisis del significado lingüístico ofrecido por el modelo deíctico es que (como ya se desprendía de la discusión al final de la sección anterior) da trato excepcional a los nombres propios frente al resto de expresiones para las que existen convenciones o estipulaciones nominales. Dicha excepcionalidad reside en que, por un lado,

${ }^{21}$ Las razones por las que esto no se cumple en muchos casos (aunque conviene resaltar que no siempre es así: piénsese en los nombres de asteroides y otros cuerpos celestes menores - asignados por la IAU-) no son de índole semántica. En el caso de los nombres propios de personas, además de razones prácticas, influyen notablemente condicionantes culturales y sociales. En todo caso, las razones pertinentes se encuadran en el tipo de explicación que indaga por qué determinadas palabras han llegado a tener los significados que tienen, y pertenecen, propiamente, a la metasemántica, según la conocida distinción trazada por Kaplan (1989), y, con otros términos, por Stalnaker (1997). Véase la sección 4.2 (ii).

Por otra parte, Segal $(2001, \S 5.2)$ discute algunos interesantes datos empíricos que apuntan a que los niños esperan, por defecto, que al nombre propio le corresponda sólo un portador.

${ }^{22}$ Aunque simple, sorprende (hasta donde conozco) que esta razón haya sido poco resaltada. 
(el) se excluye el elemento fijado en la práctica convencional, el valor semántico, del significado lingüístico de la expresión (tipo); y, por otro,

(e2) se dota a la expresión (tipo) de un calificador descriptivo (en la línea de (M)) que, fundamentalmente, atribuye al designátum la propiedad o condición metalingüística de ser portador del nombre (de ser objeto de una estipulación nominal).

(En realidad, puede decirse que ambos respectos son dos caras de la misma moneda - como cabrá apreciar en su justificación-.)

La objeción basada en la excepcionalidad se inscribe (de modo amplio) en un tipo de razón que se conoce como argumento de generalidad, que ya fue utilizado por Kripke, y constituye una de las más importantes objeciones para los enfoques metalingüísticos en general, y para el modelo deíctico, en particular. ${ }^{23}$ Este tipo de objeción basa su fuerza en que las razones aducidas para justificar el patrón de significado lingüístico atribuido a los nombres propios puedan ser generalizadas y extendidas a otras categorías de expresión, para las que no se defiende dicho modelo. ${ }^{24}$ Un presupuesto del mismo es la consideración de que ciertos elementos relativos a la constitución del significado que son comunes a distintas categorías gramaticales deben recibir un tratamiento semántico uniforme. Esto parece un desiderátum razonable, y la dificultad del modelo deíctico es que no lo respeta.

El partidario del modelo deíctico (o del metalingüístico) debe, por lo tanto, dar alguna razón que logre separar el caso de los nombres propios de esas otras categorías de expresiones que cuentan con estipulaciones nominales. Examinaremos a continuación dos líneas

${ }^{23}$ Las otras dos objeciones clásicas a los modelos metalingüísticos son el argumento modal y la objeción de circularidad (ambas de Kripke 1980). Es obvio que la primera no afecta al modelo deíctico pues éste suscribe la tesis de referencia directa (T1). Aunque quizá no tan obvio, tampoco es objeto de circularidad, justamente por la intervención de las cadenas de comunicación (T2). La explicación de cómo hace referencia vía (M) un uso de un nombre no pretende dar cuenta de la noción misma de referencia; antes bien esa explicación fundamenta ese uso en otros actos de referir: el de los actos de nominación en los que se asienta la práctica.

${ }^{24}$ Kripke (1980, p. 69) criticaba un razonamiento particular de Kneale, por el que se justificaba que el significado de un nombre propio como "Sócrates" fuera "se llama "Sócrates" en virtud de que resulta trivial decir que Sócrates se llama "Sócrates". El reparo de Kripke era que, entonces, lo mismo habría que concluir de nombres comunes como "caballo". En Kripke 1979 (pp. 139-140, n. 12) presenta una versión modificada, que involucra la noción de sinonimia, del mismo tipo de argumento (que se discutirá más adelante en la sección 4.2). 
principales de respuesta con las que se trata de defender la excepcionalidad planteada para los nombres propios, y de neutralizar, así, el argumento de generalidad. El tipo de razón que se aduce en ambos casos se fundamenta en el intento de explicar algún aspecto relativo a la competencia lingüística de los hablantes. Sin embargo, como trataré de mostrar, estas razones (sin negar los fenómenos apuntados) no me parecen suficientes para justificar la alteración del modelo de significado lingüístico, y salvar con ello la objeción de generalidad.

\subsection{Convenciones sociales y localidad}

Récanati (1993, $\S \S 8.2$ y 8.4) justifica la excepcionalidad representada por los nombres propios sosteniendo que las estipulaciones nominales, en su caso (a diferencia de las de nombres comunes o adjetivos), no son convenciones lingüisticas, sino sociales. Son un simple elemento del contexto. "El modelo deíctico se basa [...] en la afirmación de que las convenciones de los nombres son parte del contexto antes que parte del lenguaje" (p. 143). ${ }^{25}$ De ahí la asimilación a los deícticos, por cuanto la "referencia del nombre depende $[\ldots]$ de un factor contextual, tal como hace la referencia de una expresión deíctica" (p. 140). Así, se explicaría la singularidad señalada en (el), de que lo fijado por la convención (el valor semántico) sea excluido, en los nombres propios, de su significado lingüístico. (Obsérvese, por otro lado, cuán cerca está la afirmación de Récanati de una idea familiar: la de que los nombres no son parte del lenguaje. $)^{26}$

¿Pero qué motivo puede haber para aceptar esto? Récanati ofrece la siguiente razón: "Las convenciones de los nombres no parecen ser

${ }^{25}$ El carácter social de las estipulaciones cuadra mal con lo observado en la sección 2 (ii) de que no cabe hablar de que una expresión (tipo) se instituya en un nombre propio hasta que se apoya en una práctica de uso que se constituya en una convención o estipulación nominal.

${ }^{26}$ Propiamente, Récanati no defiende tal extremo. Al fin y al cabo, los deícticos sí son parte del lenguaje. Consecuentemente afirma que aunque la convención nombreportador (la estipulación nominal) es social y no lingüística, sí es una convención lingüística la general de que un nombre se refiere a su portador (nuestro (M)). Es decir: el nombre (tipo) sí es parte del lenguaje; pero no sus estipulaciones nominales. Un ejemplo explícito de la tesis de que los nombres no pertenecen al lenguaje se encuentra en el enfoque metalingüístico de Bach (2002, p. 82). Éste afianza la tesis aduciendo que los nombres no se incluyen en los diccionarios, algo que defiende también Pelczar (2001, p. 134). La (bastante frecuente) apelación a los diccionarios para decidir sobre el carácter semántico de los nombres no me resulta convincente por motivos en los que no puedo extenderme ahora. Sólo diré que resulta sorprende en un defensor de un análisis deíctico de los nombres como es Pelczar, ya que no parece tener en cuenta que los diccionarios sí recogen las expresiones deícticas (tipo), pero no los nombres (tipo). 
convenciones lingüisticas porque no es necesario conocer al portador de un nombre como 'Aristóteles' o 'Ralph Banilla' para dominar el lenguaje" (p. 144). Con ello la competencia en los nombres propios se limita estrictamente al conocimiento del calificador descriptivo (M); y nada relativo a una aplicación particular suya es parte de esa competencia. ${ }^{27}$

Un modo de reconstruir el argumento detrás de esta razón sería:

(R): (a) Si los referentes pertenecieran al significado lingüístico de los nombres propios, entonces los hablantes competentes habrían de conocer todas las estipulaciones nominales relativas a estas expresiones.

(b) Pero, como es natural, nadie está al corriente de todas estas estipulaciones nominales. (¡Tal es la cantidad de estipulaciones vigentes!)

(c) En consecuencia, el significado lingüístico de los nombres no incluye a los referentes.

En este razonamiento está implícito el siguiente supuesto fundamental que sirve de apoyo a la premisa (a):

(s) Un hablante competente debe conocer el significado lingüístico de todas las expresiones de la lengua que habla.

La dificultad del razonamiento estriba en la rigidez del supuesto (s), que establece una condición extremadamente fuerte para determinar la competencia lingüística. En principio, es dudoso que el conocimiento del significado lingüístico de toda expresión sea el criterio que determine la competencia lingüística. Veamos un par de razones, una específica para el caso de los nombres propios y otra general, que sugieren una flexibilidad del umbral de competencia.

${ }^{27}$ En realidad, en las razones de Récanati confluyen dos elementos: (i) no es preciso conocer a los referentes o las estipulaciones para ser competente respecto al nombre $N$; y (ii) basta el conocimiento de (M) para ser competente en el nombre $N$. En el texto sólo proseguiremos el primer hilo. Tratar debidamente la cuestión de la competencia de los nombres propios excede (y nos aleja) de los objetivos de este trabajo. Obsérvese, no obstante, que por (ii) no hay tal cosa como ser lingüísticamente competente en el nombre "Aristóteles" en cuanto nómbre del filósofo de Estagira, pero no serlo, por ejemplo, referido al armador millonario. La idea me parece discutible. ¿No cabe hablar de incompetencia en casos prominentes, como por ejemplo, respecto de nombres de personas íntimas o famosas? Véase la nota 33. 
En primer lugar, la institución de los nombres propios posee una idiosincrasia particular. Su función, o razón de ser, dentro del lenguaje es eminentemente práctica, de agilidad comunicativa: favorecer la introducción de objetos en el discurso más allá de los estrechos márgenes delimitados por los (genuinos) deícticos y las descripciones definidas. Un indicio claro de esto es la mencionada permisión con la que se concede a cualquier hablante instaurar nuevas estipulaciones nominales (que no hallamos en ninguna otra categoría de expresiones). Ahora bien, la necesidad de hablar de algunos objetos, y de disponer de nombres para ellos, es relativa a las necesidades de las personas. La cantidad de objetos que una persona llega a conocer es pequeña (relativamente a los que hay), y menor aún la de aquellos por los que se muestra interesada. Todos estos factores contribuyen a explicar por qué es admisible con estas palabras la ignorancia de muchas estipulaciones nominales. ${ }^{28}$

En segundo lugar, y lo que es más importante, los nombres propios no presentan la única excepción a (s). La flexibilidad del umbral de competencia es apreciable también en otros tipos de palabras, como, por ejemplo, en muchos nombres comunes. Como señaló Putnam (1975, pp. 248s.), factores de tipo social y cultural actúan sobre el umbral de competencia lingüística de modo variable, según sea la palabra de la que se trate. Así, la riqueza de los estereotipos asociados con los términos de género o sustancias naturales oscila de unos casos a otros (por ejemplo, el estereotipo de "agua" es más rico que el de "mercurio"); y, en algunos casos, se llega al extremo de que se dispensa al hablante ordinario del conocimiento del término mismo, no sólo de su estereotipo (como con "molibdeno", "hafnio" o "radón").

Récanati $(1993, \S 8.5)$ dispone de una réplica para la dificultad que plantean a $(\mathrm{R})$ las consideraciones (sociolingüísticas) de Putnam. A su modo de ver, lo único que muestran es que unas palabras tienen menor difusión que otras. Forman una gradación, un continuo, que va desde las palabras altamente centrales (de estereotipo rico) hasta las muy locales (cuyo estereotipo, para el hablante medio, es pobrísimo o desconocido; o simplemente el hablante desconoce el propio término). Voces técnicas (al igual que las dialectales) serían, en este sentido, localismos. Récanati ahonda en esta consideración para justificar el modelo deíctico: los nombres propios serían también localismos.

\footnotetext{
${ }^{28}$ Lo que no implica que no deban conocerse los nombres propios en cuanto categoría lingüística.
} 
Lo que es especial en los nombres propios, diría yo, es su carácter esencialmente local: caen en el final "pobre" del continuo. Nombres propios como "Putnam" o "Banilla" son como términos técnicos especializados: no se requiere que un usuario común de la lengua conozca nada sobre la extensión de tales palabras -incluso no se requiere que conozca que existen - ${ }^{29}$ (Récanati 1993, p. 148)

Por ello las convenciones que ligan los referentes a los nombres propios "no están entre las reglas semánticas constitutivas" del inglés o del castellano. Antes bien, pertenecen a "una extensión" de estas lenguas; de modo semejante a como "distinguimos el inglés ordinario de la lengua, digamos, de los informáticos (angloparlantes), que consiste en el inglés más un conjunto de palabras técnicas desconocidas para el usuario común del inglés" (1993, p. 148).

Ahora bien, este razonamiento dista de prestar apoyo al modelo deíctico en su pretensión de justificar (el). Dos son las razones. En primer lugar, no se aprecia por qué el mero hecho de que una palabra pertenezca a una nomenclatura o extensión de una lengua haya de dar lugar a una distinción en la estructura de su significado lingüístico - como la representada por (el) - respecto de aquellas que pertenecen al cuerpo principal de la lengua. Esto queda claro en el caso de los nombres comunes: ni la centralidad de "agua" o "barco", ni la localidad de "radón" o "varenga" afectan el carácter lingüistico tanto de sus estipulaciones nominales como de sus extensiones. Pero si la localidad (esencial) de los términos técnicos especializados no basta para adoptar con ellos (el), tampoco habría de bastar en el caso de los nombres propios. Con esto vemos que la argumentación de Récanati no logra escapar a la objeción de la generalidad..$^{30}$

En segundo lugar, obsérvese además que, como señala el propio Récanati, el carácter central o local de una palabra (la dispensabilidad o no de su conocimiento) es gradual. Lo que, por tanto, no logra explicar adecuadamente un cambio cualitativo en el significado lingüístico de las expresiones: el salto que media entre que algo sea un elemento lingüístico o un elemento puramente contextual; más aún si

${ }^{29}$ Aunque - reconoce - hay nombres que gozan de mayor nombradía que otros, considera que todos son localismos, pues son escasísimos aquellos cuya vigencia tiene un alcance espacial o temporal similar al que poseen, generalmente, el resto de las voces de una lengua.

${ }^{30}$ Véase la nota 26 para atenuar la tentación de añadir como factor diferenciador de que la estipulación de "radón" sea lingüística, pero no la que vincula el nombre (tipo) "Aristóteles" con el filósofo de Estagira, el hecho de que sólo la primera se recoge en los diccionarios. 
tenemos en cuenta que por el avance de la ciencia una misma palabra puede ir progresivamente especializándose (como observó Putnam), y desplazándose por ese continuo. ${ }^{31}$

Con lo que la razón basada en la competencia y la dispensabilidad del conocimiento de los nombres propios no es suficiente para negar el carácter lingüístico de sus estipulaciones nominales y con ello la exclusión de la referencia del significado lingüístico; y no permite, en definitiva, justificar el modelo deíctico.

\subsection{Propiedad metalingüística y prácticas}

Si la exclusión del referente en los nombres propios no está justificada, parece diluirse la necesidad de que haya un calificador descriptivo que sirva para guiar la obtención de un referente en el contexto. No obstante, la presencia de un componente como (M) suele ser justificada de modo independiente. Sea o no el referente parte del significado lingüístico, se considera que sí debe serlo la información de que el referente se llama " $N$ ". La razón alegada es que de ese modo puede explicarse el conocimiento (más o menos tácito) de los hablantes de que los nombres propios tienen un portador, de que algo se llame $N$.

Pero - como defenderé - explicar que sea parte de la competencia lingüística de los hablantes este tipo de conocimiento no requiere la inclusión en el significado lingüístico de los nombres propios de un calificador en forma de regla que lo explicite. Y ello por dos tipos de consideraciones (complementarias). (i) Nuevamente, no se logra justificar la excepcionalidad (e2) que supone respecto de las otras expresiones erigidas en estipulaciones nominales. (ii) En la defensa de (M) se entremezclan elementos sobre el significado que pertenecen a órdenes explicativos distintos.

(i) Recordemos que el modelo deíctico debe justificar (e2) para evitar el argumento de generalidad, que aplicado al caso discurre así: si un nombre propio, como "Sócrates", hubiera de incluir en su significado lingüístico la información "se llama "Sócrates"” como explicación del conocimiento de los hablantes de que hay una práctica convencional

\footnotetext{
${ }^{31}$ Cabe contrarreplicar que los nombres están en un extremo del continuo y que en ese extremo sí se produce un cambio cualitativo. Pero eso trae de vuelta la cuestión de la generalidad, pues en ese extremo están también las voces técnicas especializadas (o típicos localismos como las apelaciones locales de alimentos — "aubergi", "trumfo"-). Todo esto sin contar, por otro lado, con que parece haber nombres propios a los que difícilmente puede negárseles un carácter central ("Jesucristo", "Barcelona"), pero véanse las notas 29 y 27.
} 
de usar dicha expresión para referirse a cierto individuo, otro tanto habría que decir de un nombre común, como, por ejemplo, "caballo".

La justificación de (e2), en palabras de Kent Bach (1987, p. 136), es la siguiente: “¡no hay nada más para ser significado por el nombre! Mientras los caballos son llamados 'caballos' porque cada uno de ellos tiene la propiedad de ser un caballo —es otro asunto que esta propiedad sea expresada por la palabra 'caballo'-, Sócrates es llamado 'Sócrates' porque tiene la propiedad de portar el nombre "Sócrates'." "32

Conviene, antes de nada, aclarar la argumentación, y especialmente la afirmación de que Sócrates es llamado "Sócrates" porque porta ese nombre. La idea parece ser ésta: mientras un hablante competente debe saber, al entender un uso de un nombre como "caballo", que la clase denominada cumple (faliblemente) con cierto estereotipo; en el caso de un nombre propio, el hablante no dispone de otra cosa que su conocimiento general de las prácticas de nombrar objetos.

Ante esto, caben dos réplicas, dirigida cada una a un aspecto de la razón apuntada. En primer lugar, no está de más puntualizar que sí hay algo que puede ser significado por el nombre propio: el objeto. Otra cosa es que se quiera añadir al significado algo más, de la misma manera que "caballo" incorpora, junto a su extensión, un estereotipo. Pero centrándonos en la línea argumental de que no hay tal cosa como un estereotipo que le quepa conocer al hablante, tampoco debe olvidarse que cada hablante cuenta con su propia concepción acerca del objeto al que se aplica el nombre. Que no haya modos convencionalmente sugeridos de pensar en el referente, que no haya algo como un estereotipo, no comporta que cada hablante, al adquirir el nombre, no haya ido conformando su particular manera de pensar en él. La ausencia de un estereotipo supone simplemente que las

${ }^{32}$ Véase también Bach 2002, p. 76. Idea parecida fue apuntada por Tyler Burge (1973, p. 430): "el nombre mismo forma parte de las condiciones bajo las cuales es aplicable. [...] Un objeto podría ser un perro incluso si la palabra 'perro' nunca hubiera sido utilizada como símbolo. Pero un objeto no podría ser un Jones a menos que alguien usara 'Jones' como nombre." Por otra parte, Bach (1987) ofrece aún otra razón: si el ser llamado con cierta expresión no fuera parte del significado del nombre, no tendría sentido mantener que hay usos no literales de nombres (en el que un nombre es aplicado a un individuo para el que no hay una práctica de referirse con ese nombre). Pero esta razón, obviamente, puede ser generalizada. Récanati (1993, §9.4), por su parte, recurre de nuevo con (e2) a que la convención de "caballo" es lingüística, y las de "Sócrates", no; pero ya hemos visto las dificultades de esta posición. 
propiedades perceptuales o descriptivas del objeto de que se valen los hablantes son variadas. ${ }^{33}$

En segundo lugar, sin duda con (M) se trata de poner de relieve el conocimiento (siquiera tácito) que tienen los hablantes del papel fundamental que, en la adecuación del nombre propio a un objeto, desempeña el que éste satisfaga la propiedad metalingüistica. Esto es la propiedad de estar involucrado por una práctica de uso de la expresión para hacerle referencia; de manera que el acto de hacer referencia al objeto (con el uso del nombre) no está desconectado de anteriores actos referenciales, sino que depende de esos otros usos de la misma expresión (tipo). Pero de nuevo la objeción es clara: esta justificación de la pertinencia de (M) no alcanza a neutralizar el argumento de generalidad. En expresiones como "caballo" o "agua" encontramos la consiguiente propiedad metalingüística. Y en su caso tal propiedad resulta igualmente clave para la explicación de un elemento fundamental de la competencia de los hablantes con este tipo de expresión. Pues justamente ese elemento esclarece lo que está detrás de las intuiciones semánticas explotadas en los argumentos externistas (kripkeanos o putnamianos); es lo que explica, por ejemplo, que no se considere que porciones de cierta sustancia vayan a ser agua por el mero hecho de satisfacer los rasgos incluidos en el estereotipo asociado al nombre común "agua", sino que se espere que porciones de la misma sustancia hayan sido así denominadas en anteriores actos de nominación pertenecientes a la cadena de comunicación originada por la misma práctica lingüística.

Creo que estas consideraciones revelan suficientemente que nos hallamos ante un ingrediente de la competencia lingüística de los hablantes sobre el funcionamiento semántico de ciertas expresiones - un aspecto del significado de los que llamé categoriales-, que es compartido por varias categorías de expresiones. Una pregunta legítima es cómo debe ser articulado este conocimiento en la teoría semántica (abordo esta cuestión en (ii)). Lo lógico, en todo caso, por las razones observadas, sería conferirle un tratamiento uniforme para los distintos tipos de expresiones. La pretensión del análisis deíctico, sin embargo, es otorgarle un lugar privilegiado en el significado de

${ }^{33}$ Esa concepción (varia, y más o menos rica, según los casos) es parte de lo que hace sentir competente a un hablante respecto de una práctica de uso de un nombre. Por ejemplo, conocer más o menos datos del filósofo de Estagira o ser capaz de reconocer al millonario o haber oído hablar de él. Está claro que eso no determina la referencia, pero tampoco lo hace el estereotipo. Agradezco a Genoveva Martí haberme llamado la atención sobre estas consideraciones. 
los nombres propios con relación al resto de las expresiones. Y tal desajuste, como se ha visto, no está debidamente justificado.

Es preciso en este punto hacer una salvedad respecto al particular modelo que presenta García-Carpintero en "The Mill-Frege Theory of Proper Names" (inédito), pues en su caso atribuye también como parte del significado lingüístico de los términos generales la mencionada propiedad metalingüística, con lo que, en principio, parece a resguardo de alguna de las consideraciones recién apuntadas. ${ }^{34}$ Veamos cómo defiende la crítica de la generalidad. Su modo de abordar la dificultad mantiene ciertas semejanzas con la réplica de Bach. Ahora bien, García-Carpintero se enfrenta a la argumentación de la generalidad en la versión particular de Kripke (1979, pp. 139-140, n. 12), según la cual el hecho de que consideremos que "alienista" y "psiquiatra" son sinónimos mostraría que no contamos "ser llamado "alienista" " o "ser llamado "psiquiatra" " como parte del significado lingüístico de, respectivamente, "alienista" y "psiquiatra"; con lo que otro tanto habría que decir de "ser llamado "Cicerón" " o "ser llamado "Tulio" " en relación con los nombres propios "Cicerón" y "Tulio". La réplica de García-Carpintero se basa en que la analogía planteada en la argumentación kripkeana se rompe en la medida en que los términos comunes cuentan como parte de su significado lingüístico con un estereotipo, pero no los nombres propios.

Con unos términos y otros, ser plenamente competente con la voz léxica requiere conocer (siquiera tácitamente) la práctica convencional que constituye la estipulación nominal. Pero hay una diferencia: mientras que para ser competente en relación a un término común (tipo), además de la propiedad metalingüística, es preciso conocer los rasgos que guían los actos de nominación en la fijación de la referencia y que conforman el estereotipo, en relación a un nombre propio (tipo), por el contrario, basta meramente el conocimiento de la propiedad metalingüística. ${ }^{35}$ Con relación a la práctica convencional que involucra al nombre propio, al hablante le basta conocer (tácitamente) que debería haber actos de nominación que la instancien,

\footnotetext{
${ }^{34}$ Agradezco a un evaluador anónimo la sugerencia de discutir la posición de García-Carpintero (inédito).

${ }^{35} \mathrm{La}$ salvedad de que la competencia es sobre el tipo de expresión proviene de que entender un ejemplar proferido requiere algo más, que es sólo aportado contextualmente, como se explica de los nombres propios en el texto (y se volverá a tratar en la sección 5). Con ello se distingue entre la competencia con el tipo de nombre "Alberto", y la comprensión de un uso particular de esa expresión; análogamente a como se distingue la competencia con la expresión tipo "yo", por contraste con la comprensión de un uso particular de un ejemplar del pronombre.
} 
pero sin haber de conocer en virtud de qué rasgos o procedimientos se producen tales actos. En definitiva, según García-Carpintero, este contraste basta para explicar la intuición de que, en el caso de los términos comunes como "alienista" y "psiquiatra", la coincidencia en los rasgos involucrados en el establecimiento de los actos de nominación de ambas prácticas lleva a pensar que son sinónimos, a pesar de las diferencias en sus respectivas propiedades metalingüísticas. Y con ello el efecto de la analogía de Kripke se vería aminorado.

En mi opinión, esta versión kripkeana particular del argumento de generalidad es la más débil, y resulta pertinente para esta constatación el contraste apuntado por García-Carpintero. No obstante, estas razones no dispensan por sí solas la argumentación más general que se viene discutiendo. ${ }^{36} \mathrm{Y}$ en particular, es objeto de la crítica a la que apunta la reflexión que sigue en (ii).

(ii) El acento que el modelo deíctico pone en el conocimiento de las prácticas convencionales en las que se constituyen las estipulaciones nominales por parte de los hablantes no está en tela de juicio. Es un hecho que debe ser atendido. Lo que está en duda - como decía- es cómo debe hacerse. Mi intención aquí es apuntar una reflexión que intenta poner de manifiesto lo inadecuado del modo de afrontarlo emprendido por el modelo deíctico.

${ }^{36}$ A pesar de que los términos generales para García-Carpintero (inédito) son también reflexivos del ejemplar, poseyendo una regla que incluye la mención de la propiedad metalingüística, ello no supone, según creo, la adopción para estas expresiones de un modelo deíctico. Las diferencias con los nombres propios son notables: cada voz léxica posee una regla propia que incluye los rasgos de su particular estereotipo. Como resultado (salvo excepciones, como en los ejemplos putnamianos de la Tierra Gemela), a cada regla le corresponde una práctica convencional y, por lo tanto, un valor semántico. Lo que es compatible con decir, como he venido haciéndolo en el texto (por simplificar), que el tipo tiene asociado un valor semántico. (Por contraste, en los nombres propios — según el modelo deíctico - todas las prácticas convencionales se relacionan con la misma regla (M).) Que en general las expresiones (categoremáticas) sean reflexivas del ejemplar en su análisis es un modo de explicar que es a las proferencias de esas expresiones a las que propiamente cabe atribuir valores semánticos y condiciones de verdad. Pero esto es perfectamente asumible y compatible con las posiciones de los partidarios del modelo ingenuo, como cabe apreciar en Perry 1988. Un nombre propio, en el análisis de García-Carpintero (inédito), no se inscribe en el modelo deíctico por ser meramente reflexivo del ejemplar en este sentido, sino por el hecho de que un mismo nombre con una misma regla lingüística puede obtener un referente distinto en cada ocasión de uso de un modo que remeda, en parte, el funcionamiento de los deícticos genuinos. Algo que no ocurre con los términos generales. (Téngase presente lo dicho en el segundo párrafo de la nota 1.) 
Lo discutible de la propuesta realizada por este modelo es que al recoger el conocimiento de esas prácticas convencionales en (M), lo sitúa al mismo nivel que ocupan en el significado lingüístico de ciertos tipos de expresión elementos tales como una referencia o extensión, un estereotipo o la regla que (en los deícticos) procura la obtención contextual de un referente. Creo que con ello se están confundiendo órdenes de cosas distintos en relación con el significado, pues el papel que desempeñan las prácticas convencionales debe ser situado en un nivel más fundamental (que el de esos otros ingredientes).

Para apreciarlo conviene que consideremos cuál es la función explicativa del expediente de las prácticas convencionales que determinan cadenas de comunicación; y que lo hagamos (ahondando en la pauta abierta por Almog (1984)) desde un punto de vista más general, sin limitarnos únicamente a las prácticas que originan estipulaciones nominales. ${ }^{37}$ Esta función no es otra que la de explicar, por un lado, cómo se fijan ciertos elementos del significado de una expresión (tipo); y, por otro, cómo se preserva el significado a lo largo de los distintos usos que se hacen de ella. Este segundo aspecto resulta especialmente relevante para la discusión actual por cuanto es el que explica cómo esos distintos usos se corresponden (los últimos con los anteriores), conformando una unidad semántica. ${ }^{38}$

Este mecanismo explicativo, como hemos visto sobradamente, se halla, en una de sus formas, en los nombres propios y en las otras categorías de expresiones asentadas en estipulaciones nominales. Lo característico con estas expresiones es que dicho mecanismo, en la medida en la que en su caso lo fijado y preservado por la práctica es un valor semántico para la expresión (tipo), explica que todas estas categorías de expresiones no sean expresiones de una sola vez.

Pero las prácticas que se constituyen en estipulaciones nominales sólo son un tipo de prácticas convencionales. El aspecto crucial al que conviene atender ahora es que también los deícticos se asientan en prácticas que determinan una cadena de comunicación. Sólo que en su caso, en cuanto expresiones de una sola vez, lo fijado y preservado no es el valor semántico (el referente), sino el calificador descriptivo en forma de regla que ha de procurarle uno. Pero esta práctica convencional da cuenta de igual modo de la unidad semántica de la expresión. Que la práctica no se constituya en una estipulación nominal (como la de los nombres en general, que los vincula al objeto o

${ }^{37}$ El análisis de Almog (1984) sobre la función de las cadenas (causales) de comunicación es clave para la crítica que planteo a continuación.

${ }^{38}$ En virtud de la cadena (causal) de hablantes que toman unos de otros una expresión, y de la intención de éstos de ajustarse al uso heredado. 
la clase de objetos a los que se aplican) sólo debe contribuir a desembarazarnos de la idea de que la cadena de comunicación constituye esencialmente un mecanismo explicativo de la designación (o de la fijación del valor semántico) y no del significado, en general (como señaló Almog). ${ }^{39}$

Si tenemos presente esta función básica de las prácticas convencionales de preservar los distintos elementos del significado de una expresión, parece más adecuado considerar que en todos los casos es un componente del funcionamiento (y constitución) de las expresiones que debe encuadrarse en un nivel distinto, más fundamental, que aquel que corresponde a los elementos que son establecidos en virtud de él. Lo más adecuado, me parece, sería seguir la senda que incluye este componente entre los aspectos relativos al significado propios de una investigación metasemántica, antes que en una propiamente semántica. Según esta distinción, la semántica se ocuparía de los valores (o, como en el caso de los deícticos, de los tipos de valores ${ }^{40}$ semánticos que corresponden a las expresiones, y además de los elementos que hemos considerado parte del significado lingüístico de tales expresiones (así, por ejemplo, el estereotipo de los términos generales o el calificador descriptivo de los deícticos); mientras que la metasemántica explicaría los factores en virtud de los cuales una expresión ha adquirido una determinada semántica, así como las alteraciones producidas en ésta con el tiempo. ${ }^{41}$

No obstante, si en consideración a la importancia concedida por el modelo deíctico de los nombres propios a la elucidación de los aspectos (ya discutidos) sobre la competencia lingüística de los hablantes, se juzga preciso incluirlo entre los rasgos categoriales del significado lingüístico de las expresiones (y, por consiguiente, ser objeto de la semántica), entonces — como he venido defendiendodebe hacerse, por un lado, de modo uniforme y para todas las categorías de expresiones; y, por otro - como acabo de decir-, no entremezclándolo con esos elementos (como referentes, estereotipos

${ }^{39}$ Hablar sólo del referente, el estereotipo o el calificador descriptivo (de los deícticos) es una simplificación. La cadena de comunicación también preserva los ingredientes categoriales del significado lingüístico de las expresiones.

${ }^{40} \mathrm{Es}$ decir, que los deícticos son términos referenciales de acuerdo con (Tl).

${ }^{41}$ La distinción entre semántica y metasemántica fue esgrimida originalmente por Kaplan (1989). En Stalnaker 1997 se encuentra una distinción análoga, en términos, respectivamente, de "semántica descriptiva" y "semántica fundacional"; sólo que su caracterización de la semántica descriptiva es más estrecha que la ofrecida antes (lo que da como resultado una dicotomía no exhaustiva de los distintos aspectos relativos al significado), por cuanto no incluye elementos como el calificador descriptivo de los deícticos (además de otros ingredientes del significado lingüístico). 
o calificadores descriptivos) que son establecidos precisamente por las prácticas convencionales.

Contemplando la cuestión desde este punto de vista, puede apreciarse lo inadecuado que resulta aducir (como en la explicación de Bach) que el conocimiento sobre el funcionamiento de la práctica venga a cubrir o compensar, en los nombres propios, el hueco que en los nombres comunes es ocupado por el estereotipo. Es más, revela cierta falla en el intento de explicitar por medio de una regla como (M) el conocimiento (que cabe esperar o no) de los hablantes sobre el funcionamiento de las prácticas. ${ }^{42}$ Nótese, sobre esto último, que la señalada dependencia de los deícticos (genuinos) en prácticas o cadenas de comunicación no es un rasgo incluido en su calificador descriptivo.

Por ello, tratar de igualar la dependencia de un nombre propio en las prácticas de nombrar con la dependencia contextual de un deíctico en la obtención de un referente oscurece más que iluminar los distintos órdenes explicativos comprometidos en cada caso.

\section{Modos de presentación y el problema de la comprensión}

La última razón en favor del modelo deíctico se aleja del tipo de consideraciones lingüísticas tratadas hasta el momento. Tiene que ver con la comunicación y con dar una respuesta fregeana o connotativista a la cuestión de la adecuada comprensión del uso de los nombres propios. Creo no equivocarme en que este tipo de razón encierra el más importante incentivo entre los partidarios del modelo deíctico (y de los metalingüísticos en general) para la adopción de sus teorías.

El problema que se quiere afrontar parte del reconocimiento de que "la comunicación tiene que permitir la transmisión de conocimiento, o cuando menos de creencia justificada; y no, meramente, la transmisión de creencia verdadera" (Heck 1995, pp. 91-92). ${ }^{43}$

A tal fin, parece razonable (no sólo desde un punto de vista connotativista) exigir que para que haya comunicación no baste, meramente, que los interlocutores den con el referente correcto de un uso particular de un nombre propio (al ser proferida una oración que lo contiene), sino que la comprensión cabal de ese uso del nombre requiere que identifiquen al referente situándose en la misma práctica convencional a la que pertenece el uso del nombre. En una situación en la que el interlocutor yerre la práctica de uso de un nombre (que

\footnotetext{
${ }^{42}$ Salvando las distancias, el proceder que anima este intento de explicitación evoca al proceder de la Tortuga con Aquiles en la fábula de Carroll (1895).

${ }^{43}$ Véase Evans 1982 (§ 9.2) para una decidida defensa de esta tesis.
} 
sigue el hablante) por otra distinta que casualmente relacione el mismo objeto con la misma expresión (tipo), no se darían las condiciones para la transmisión de conocimiento. ${ }^{44}$

Lo que añade el diagnóstico que los enfoques connotativistas hacen de la situación es conocido: en la comunicación, un ingrediente necesario de la comprensión (genuina) es que sea accesible a los interlocutores que sus interpretaciones (de un uso particular de un nombre) coinciden; que la creencia expresada por uno y la captada por otro no difieran "en justificación epistémica desde una perspectiva epistémica suficientemente internista" (García-Carpintero 2000b, p. 310). Lo que esto trae consigo es la adopción de alguna variedad del requisito fregeano de similitud epistémica, de similitud en los modos de presentación que incorporan sus creencias, a fin de que pueda quedar de manifiesto para los hablantes que están usando el mismo nombre. En palabras de Loar (1976, p. 357): “Al parecer, como sostuvo Frege, algún 'modo de presentación' del referente es, incluso en los usos referenciales, esencial para aquello que es comunicado." 45

En "The Mill-Frege Theory of Proper Names" (inédito), GarcíaCarpintero explora en profundidad la cuestión (que ya había sido apuntada en García-Carpintero 2000b) y sostiene que el modelo deíctico se halla comprometido con esta vía de solución al problema de la comprensión y la transmisión de conocimiento (esta propuesta de solución es la que examinaré a lo largo de esta sección).

El uso del nombre por parte del hablante produce una connotación contextual. "Guiado por su conocimiento de la semántica de los nombres, [el hablante utiliza] una forma de palabras que, empleando con esta guía información contextual, permitiría que su conocimiento pasara [al oyente]" (García-Carpintero 2000b, p. 310). Así, al comprender una proferencia de un nombre propio, como al comprender la de un deíctico, alguna información contextual (lingüísticamente guiada) sobre el referente debe ser identificada por el oyente. La connotación contextual producida está constituida por la información puramente lingüística de que el referente se llama " $N$ ", en el sentido dado por (M); y, además, por algún dato predicativo que permita restringir la práctica convencional en la que se apoya el hablante de entre aquellas

\footnotetext{
${ }^{44}$ La mejor ilustración de este planteamiento la proporciona un ejemplo de Richard Heck (1995, p. 95); antes Loar (1976, p. 357) había ofrecido uno para deícticos. El antecedente original del tipo de problema se encuentra en Frege 1918 (pp. 32-33).

${ }^{45}$ Sobre el requisito de similitud epistémica, véanse también Bezuidenhout 1997, p. 198; Heck 1995, p. 102; Dummett 1975, p. 132; Frege 1918, pp. 32-33.
} 
asociadas con el tipo del nombre. ${ }^{46}$ Así, simplificando en aras de la ilustración, la connotación de "Aristóteles", al ser proferido (en una oración) por un hablante, es "el filósofo llamado "Aristóteles" "; y en boca de un segundo hablante puede ser "el millonario llamado "Aristóteles" ". Para que la comunicación pueda permitir la transmisión de conocimiento, no basta que hablante y oyente identifiquen al referente correcto, sino que lo hagan compartiendo la información contextual lingüísticamente constreñida. No basta que identifiquen el estado de cosas singular aseverado, eso sólo aseguraría la transmisión de creencia verdadera, sino que es preciso, para que pueda transmitirse creencia justificada, que el oyente capte el modo de presentación sobre el referente que, al usar el nombre, muestra tener el hablante. ${ }^{47}$

Aun sin poder tratar en profundidad el problema de la comprensión y los distintos aspectos involucrados, trataré de indicar las líneas de respuesta por las que considero inadecuado el análisis de la comprensión ofrecido por el modelo deíctico. Me ocuparé, en primer lugar, de arrojar algunas dudas sobre la idea de que captar la intención del hablante de referirse a cierto objeto supone haber de compartir algún modo de presentación. Y expondré, finalmente, una reflexión general que cuestiona el modelo ofrecido para asegurar (internistamente) la transmisión de conocimiento en la comunicación.

${ }^{46}$ El connotativismo del modelo deíctico no se debe tanto a la presencia de (M), pues es compartido por todo nombre, y no decide en los rompecabezas del valor cognitivo. Es la circunstancia de que en cada uso ese dato es enriquecido con alguna información contextual lo que conforma una connotación de pleno derecho. García-Carpintero (inédito) añade que la información contextual incluye además información sobre la clase de objeto que es el referente. Como la necesidad de que en la comunicación se precisen clasificadores no es decisiva en la discusión sobre millianismo y connotativismo (véase la nota 4), ni en la solución al problema de la comprensión, lo excluyo de la discusión ( $c f r$. Kripke 1980, pp. 115-116, n. 58).

${ }^{47}$ Ese modo de presentación no entra en el valor semántico del nombre, y no es parte de la condición de verdad, del estado de cosas aseverado (recuérdese que el modelo deíctico suscribe (T1)). Pero la creencia que (en los sujetos) representa dicha condición de verdad incorpora un modo de presentación del referente, de manera que - se argumenta - sólo si el modo de presentación de la creencia del oyente está vinculado al modo de presentación de la creencia del hablante a través de los datos contextualmente salientes, permite la transmisión de la justificación. Algo que no se produce en los ejemplos tipo Heck. Por otro lado, Récanati (1993, $\S 3.4$ y 10.5) discute el problema de la comprensión en esta línea sólo con relación a los deícticos (a raíz del caso discutido por Loar (1976)), pero todo hace pensar que la lección es extensible a los nombres. 


\subsection{Modos de presentación comunes}

La propuesta del modelo deíctico sobre la comprensión tiene dos aspectos: (i) en cada uso de un nombre, los interlocutores deben coincidir en un dato contextual relativo al referente; y (ii) el hablante debe ser capaz de una suerte de previsión de que su uso del nombre va a incidir en un dato contextual accesible al oyente.

Cabe plantear algunas dudas acerca de ambos aspectos. No parece posible que, en general, se pueda aislar, ante una proferencia dada, un elemento predicativo como el semánticamente indicado para fundamentar la comprensión. Obsérvese que lo que este modelo plantea no es que algún dato pueda dar pistas a los oyentes sobre la práctica a la que pertenece el nombre (lo que es razonable), sino que sea una necesidad semántica que el uso del nombre vaya apoyado en algún dato tal (como en el caso de los deícticos) para que quede fijado ante el oyente lo aseverado. Lo que se afirma (y lo que está en duda) es que eso sea parte del mecanismo designativo de los nombres.

¿Por qué no parece posible? Por un lado, porque son muy variados los elementos que pueden servir al oyente para restringir la práctica pertinente. Por otro, porque que un dato pueda cumplir dicha función depende en última instancia de lo que conozca el oyente sobre el referente. Ambos factores, al conjugarse, dificultan tanto que un hablante pueda prever las posibles variaciones de conocimiento que se dan en sus oyentes, como que los interlocutores puedan compartir un modo de presentación.

Veamos un ejemplo que ilustra las dificultades de (i) y (ii). Un conferenciante profiere:

(1) Áyax pretendió a Casandra como botín en el saqueo de Troya.

Su audiencia ha de identificar a uno de los dos guerreros así llamados de la Guerra de Troya. Pero sucede que un oyente, $A$, se fija en el dato de que participó en el saqueo de Troya (sabe que el hijo de Telamón se suicidó antes de la toma de Troya); y otro, $B$, repara en el dato sobre Casandra (sabe que el hijo de Oileo la violó en el saqueo). Cada uno ignora el dato que sirve al otro, y se sirve, así, de un dato diferente para restringir la práctica pertinente.

Estas circunstancias (nada excepcionales) parecen impedir que los hablantes tengan generalmente un control efectivo (siquiera tácito) sobre los datos que pueden resultar pertinentes a su audiencia en la comprensión (contra (ii)). (En muchos casos, sólo tendrán una vaga idea de lo que resultará pertinente.) En el ejemplo, quizá el 
conferenciante mencionó que Áyax era locrio, y quiso servirse de esa información ante su audiencia. Pero $A$ y $B$ la ignoraban. Además, cabe que algunos de los datos de los que se sirve la audiencia sean desconocidos para el hablante (como los utilizados por $A$ y $B$ ). En este caso, ni el conferenciante ni $A$ ni $B$ comparten una información capaz de restringir la práctica. ${ }^{48}$ Pero parece, a todas luces, que hay comprensión (contra (i)). Negarlo haría rigurosísimas las condiciones para ésta. ${ }^{49} \mathrm{Al}$ fin y al cabo, tanto $A$ como $B$ han captado el estado de cosas aseverado, se han situado en la práctica adecuada de uso del nombre, y tienen buenas razones (basadas en su conocimiento de los guerreros en cuestión) para pensar que su interpretación es la correcta. ${ }^{50}$

El modelo deíctico de comprensión con ello desatiende una característica fundamental de la institución de los nombres propios (que los hace útiles más allá de los estrechos márgenes que habilitan los genuinos deícticos $-\mathrm{o}$ las descripciones-). Y es que pueden ser utilizados sin necesidad de que el hablante esté al corriente de las razones concretas por las que el nombre le es conocido al oyente. Por lo común, suele ser suficiente cierta presunción general de que el nombre de un modo u otro le será conocido al oyente, tal vez por simple proximidad cultural o vecinal. Lo cual no determina un único espectro de noticias que el oyente debe tener sobre el referente.

\subsection{Comprensión y justificación}

La elucidación de la comprensión de los nombres efectuada por el modelo deíctico no es más que un reflejo de su aproximación al problema de la transmisión de conocimiento. Si la comunicación es concebida como si la tarea del oyente fuera seguir un rastro hecho manifiesto por el hablante es por el intento de incluir, en la comprensión, un componente internista, accesible al conocimiento de los hablantes ( $\sin$ menoscabo de la condición externista de situarse, de hecho, en la misma práctica de uso del nombre), que posibilite la

${ }^{48}$ Comparten, seguramente, "héroe griego", "personaje homérico" o "ser de ficción"; pero nada de esto es relevante para restringir la práctica.

${ }^{49}$ Dejando a un lado situaciones cotidianas como la del ejemplo, impediría que se pudieran comprender soliloquios (o conversaciones) a los que se asiste furtivamente.

${ }^{50}$ Los interlocutores tienen (como quiere el connotativista) razones que apoyan su interpretación de que se están entendiendo (el hablante puede también tener razones generales a favor); sólo que no comparten un dato contextual, como pretende el modelo deíctico. Por eso, incluso desde el connotativismo difícilmente se puede negar que haya comprensión. 
comprensión justificada. ${ }^{51}$ Con ello, la justificación (en la comprensión) se construye como un proceso garantizador inferencial (ya sea real o tácito) que respalda la presunción de los interlocutores de que se están entendiendo Y la situación del hablante corriente que se desenvuelve dentro de su comunidad lingüística se asimila a la situación del que explora un habla ignota, y ha de apoyar con juicios su labor interpretativa.

Esta aproximación (fregeana) al problema de la comprensión me parece incorrecta por diversas razones, pero me limitaré aquí a apuntar un bosquejo alternativo, que creo mucho más apropiado. ${ }^{52}$

En condiciones normales, el intercambio lingüístico no requiere, en realidad, un tipo de proceso garantizador como el descrito. Más bien, cabe considerar que la comprensión está justificada por defecto, y sólo cuando alguna circunstancia nos previene en contra, se hace preciso algún tipo de respaldo. La situación de partida en la comunicación se corresponde con esta expresada por Tyler Burge (1993): "Si algo es prima facie inteligible, uno tiene derecho [entitled] a confiar en que su comprensión de ello es inteligible. Tiene derecho a empezar con la supuesta comprensión que uno tiene" (p. 471). Y: "Comprendemos aquello que parece que comprendemos. O, más bien, si el resto permanece igual, no necesitamos recurrir a una distinción entre comprender y parecer que se comprende. No necesitamos tomar lo que oímos como un objeto de interpretación, a menos que se suscite algún motivo de duda" (p. 488).

Así, la justificación de la comprensión no proviene tanto de que esté apoyada por un acopio de razones, como de que no haya razones para dudar de ella. ${ }^{53}$ Si todo va bien, el oyente no necesita reafirmarse en que efectivamente está comprendiendo. ${ }^{54}$ Los hablantes se mueven

${ }^{51}$ Cfr. García-Carpintero 2000b, pp. 307-308.

${ }^{52}$ En Vicario 2001, cap. 5, examino pormenorizadamente el enfoque fregeano del problema de la comprensión y el conocimiento, y ofrezco mi propia solución milliana al mismo (cuya idea principal es que los respectivos modos con los que los interlocutores piensan en el referente deben haberse nutrido adecuadamente con información obtenida en la misma cadena de comunicación).

${ }^{53}$ En este sentido, la comprensión puede compararse a la percepción: lo percibido es ya una representación de la realidad circundante y no una serie de datos que deben ser descifrados. Cfr. Evans y McDowell 1976, pp. xxi-xxii.

54 Ciertamente, la justificación basada en la confianza es falible; pero también lo es la basada en la similitud epistémica (uno puede identificar a Áyax, en (1), como el locrio, pero puede suceder que en ese hablante, por confusión, dicho modo de presentación esté vinculado con la práctica del nombre del hijo de Telamón). Hay, sin embargo, una diferencia: en el primer modelo, los hablantes pueden no entenderse sin que hayan hecho algo lingüisticamente incorrecto por su parte. 
sobre la base de la confianza. Naturalmente, los hablantes suelen tener razones para obrar así, pero suelen ser de tipo general, y no tienen que ver con el tipo de previsión señalado en el modelo deíctico. Una de tales razones es, por ejemplo, la convicción de que cualquier discrepancia acabará por manifestarse.

En este artículo he tratado de desactivar las principales razones que respaldan el modelo deíctico (metalingüístico) de los nombres propios, favoreciendo, en su lugar, el modelo ingenuo. Uno de los ejes de la discusión ha sido la noción de significado lingüístico. He empezado por presentar algunas dificultades del modelo deíctico relativas, por un lado, a la individualización de los nombres propios, y, por otro, a la pretendida proximidad del funcionamiento lingüístico de los nombres con el de los deícticos. En relación con esto último, he procurado atajar la dificultad del modelo ingenuo ante el hecho de que un mismo tipo de expresión es objeto de multitud de estipulaciones nominales, defendiendo la explicación de la homonimia. Con especial atención he criticado las distintas líneas de réplica que desde el modelo deíctico (o metalingüístico, en general) se han ofrecido a un prominente y conocido tipo de objeción a su posición: la de generalidad. Una de las líneas que he criticado es la tesis de Récanati de que las estipulaciones nominales no son convenciones lingüísticas. Otro aspecto destacado de esas réplicas, y que motiva la adopción de un calificador descriptivo para los nombres propios, es el dar cuenta de la competencia de los hablantes con las prácticas convencionales en las que se constituyen las estipulaciones nominales. En mi opinión, ese factor debe ser atendido, no sólo ni de modo diferenciado en los nombres propios, pero encuadrando esa explicación en el ámbito de la metasemántica. Dotar a los nombres propios de connotaciones metalingüísticas (como hace el modelo deíctico) ha sido una de las más importantes estrategias para lidiar con los problemas cognitivos, y en especial (desde sus orígenes) con el de la comprensión y la transmisión de conocimiento en la comunicación. Aquí he defendido que el modelo deíctico no logra, a la postre, resolver el problema, y he indicado alguna razón de por qué esa estrategia (general) está mal encaminada. 55

\footnotetext{
${ }^{55}$ Este trabajo es parte de las investigaciones enmarcadas en proyectos financiados por diversas instituciones públicas españolas: el programa CONSOLIDER-INGENIO 2010 (CSD2009-00056) y los proyectos HUM2006-09923/FISO y FFI2008-06164-C0201 correspondientes al Ministerio de Ciencia e Innovación; el Grupo Consolidado LOGOS (2009 SGR 1077) del DIUE (Generalitat de Catalunya); y el proyecto VA077A07 de la Junta de Castilla y León. Mi interés y mi comprensión del modelo deíctico son enormemente deudores de fructíferas discusiones con Manuel García-Carpintero.
} 


\section{BIBLIOGRAFÍA}

Almog, Joseph, 1984, "Semantical Anthropology", en P. French, T. Uehling y H. Wettstein (comps.), Causation and Causal Theories, Midwest Studies in Philosophy, vol. 9, University of Minnesota Press, Mineapolis, pp. 479-489.

Bach, Kent, 2002, "Giorgione Was So-Called Because of His Name", Philosophical Perspectives, vol. 16, pp. 73-103.

- 1987, Thought and Reference, Oxford University Press, Oxford.

Bezuidenhout, Anne, 1997, "The Communication of De Re Thoughts", Noûs, vol. 31, no. 2, pp. 197-225.

Burge, Tyler, 1993, "Content Preservation", The Philosophical Review, vol. 102 , no. 4 , pp. $457-488$.

— 1973, "Reference and Proper Names", The Journal of Philosophy, vol. 70 , no. 14 , pp. 425-439.

Carroll, Lewis, 1895, "What the Tortoise Said to Achilles", Mind, vol. 4, no. 14, pp. 278-280.

Dummett, Michael, 1975 (1980), "Frege's Distinction between Sense and Reference", Truth and Other Enigmas, Harvard University Press, Cambridge, Mass, pp. 116-144.

Evans, Gareth, 1982, The Varieties of Reference, ed. J. McDowell, Oxford University Press, Nueva York.

Evans, Gareth y John McDowell, 1976, "Introduction", en G. Evans y J. McDowell (comps.), Truth and Meaning: Essays in Semantics, Clarendon Press, Oxford, pp. vii-xxiii.

Frege, Gottlob, 1918, "El pensamiento: una investigación lógica", en M.M. Valdés (comp.), Pensamiento y lenguaje, trad. Carlos Pereda, Instituto de Investigaciones Filosóficas-UNAM, México, 1996, pp. 23-48.

García-Carpintero, Manuel, 2000a, "A Presuppositional Account of Reference Fixing", The Journal of Philosophy, vol. 97, no. 3, pp. 109-147.

- 2000b, "Fregean Sense and the Proper Function of Assertion: Comments on Textor", Theoria, vol. 15, no. 38, pp. 303-316.

Heck, Richard Jr., 1995, "The Sense of Communication", Mind, vol. 104, no. 413 , pp. $79-106$.

Kaplan, David, 1989, "Demonstratives", en J. Almog, J. Perry y H. Wettstein (comps.), Themes from Kaplan, Oxford University Press, Nueva York, pp. 481-563.

Katz, Jerrold J., 1994, "Names without Bearers", The Philosophical Review, vol. 103, no. 1, pp. 1-39.

Kripke, Saul, 1980, Naming and Necessity, Blackwell, Oxford. [Versión en castellano: El nombrar y la necesidad, trad. Margarita M. Valdés, Instituto de Investigaciones Filosóficas-UNAM, 1995.].

Agradezco también a Genoveva Martí sus valiosos y estimulantes comentarios a un borrador previo. Por último, quiero reconocer las indicaciones de dos evaluadores anónimos para mejorar la exposición de algunos pasajes. 
Kripke, Saul, 1979, “A Puzzle about Belief” en N. Salmon y S. Soames (comps.), Propositions and Attitudes, Oxford University Press, Nueva York, 1988, pp. 102-148.

Loar, Brian, 1976, "The Semantics of Singular Terms", Philosophical Studies, vol. 30, no. 6, pp. 353-377.

Pelczar, Michael, 2001, "Names as Tokens and Names as Tools", Synthese, vol. 128, no. 1, pp. 133-155.

Pelczar, M. y J. Rainsbury, 1998, "The Indexical Character of Names", Synthese, vol. 114, no. 2, pp. 293-317.

Perry John, 1997, "Reflexivity, Indexicality and Names", en W. Künne, M. Anduschus y A. Newen (comps.), Direct Reference, Indexicality and Proposition Attitudes, CSLI Publications, Stanford, pp. 3-19.

— 1988, "Cognitive Significance and New Theories of Reference", The Problem of the Essential Indexical and Other Essays, Oxford University Press, Nueva York, 1993, pp. 227-247.

Putnam, Hilary, 1975, "The Meaning of 'Meaning'", en K. Gunderson (comp.), Language, Mind, and Knowledge, University of Minnesota Press, Mineapolis, pp. 215-271.

Récanati, François, 1993, Direct Reference: From Language to Thought, Blackwell, Oxford.

Searle, John, 1958, "Proper Names", en A.P. Martinich (comp.), The Philosophy of Language, 3a. ed., Oxford University Press, Nueva York, 1996, pp. 249-254.

Segal, Gabriel, 2001, "Two Theories of Names", Mind and Language, vol. 16, no. 5, pp. 547-263.

Stalnaker, Robert, 1997, "Reference and Necessity", en R. Hale y C. Wright (comps.), A Companion to the Philosophy of Language, Blackwell, Oxford, pp. 534-554.

Vicario, Ignacio, 2001, Nombres, referencia y valor cognoscitivo, tesis doctoral [monografía en línea], Servei Publicacions UB, Barcelona, 2004, disponible en CBUC-Cesca/TDX < http://www.tdx.cat/TDX-0205104085747> [consulta: 13-03-2009].

Voltolini, Alberto, 1995, "Indexinames", en J. Hill y P. Kotatko (comps.), Karlovy Vary Studies in Reference and Meaning, Filosofia-Filosofia Publications, Praga, pp. 258-285.

Wittgenstein, Ludwig, 1953, Philosophische Untersuchungen / Philosophical Investigations, Blackwell, Oxford. [Versión en castellano: Investigaciones filosóficas, trad. Adolfo García Suárez y Ulises Moulines, Instituto de Investigaciones Filosóficas-UNAM, México, 1988.]

Recibido el 31 de marzo de 2009; revisado el 1 de septiembre de 2009; aceptado el 7 de septiembre de 2009. 